\title{
Effect of Artificial Shading and Temperature on Radical Scavenging Activity and Polyphenolic Composition in Sweetpotato (Ipomoea batatas L.) Leaves
}

\author{
Md. Shahidul Islam, ${ }^{1}$ Makoto Yoshimoto, ${ }^{2}$ Koji Ishiguro, Shigenori Okuno, and Osamu Yamakawa \\ Laboratory of Upland Crop Utilization, Department of Upland Farming Research, National Agricultural \\ Research Center for the Kyushu Okinawa Region, Yokoichi 6651-2, Miyakonojo, Miyazaki 885-0091, Japan
}

\begin{abstract}
ADDITIONAL INDEX WORDS. antioxidant, chlorogenic acid, caffeic acid, caffeoylquinic acid
ABSTRACT. The phenolic content and the radical scavenging activity were compared in leaves of sweetpotato (Ipomoea batatas L.) cultivars Shimon-1, Kyushu-119 and Elegant Summer grown under different temperature and shading conditions. Compared to cultivar differences, there was less effect of temperature and shading on the total phenolic content in sweetpotato leaves, however certain polyphenolic components differed widely among the treatments. The positive correlation between the radical scavenging activity and the level of total phenolics $(r=0.62)$ suggests that phenolic compounds are important antioxidant components of sweetpotato leaves. All the reverse-phase high-performance liquid chromatography (RP-HPLC) profiles of the cultivars tested showed peaks at the same retention times but peak areas of individual phenolic compounds differed with respective temperature and shading treatments. The phenolic compounds identified in the sweetpotato leaf were caffeic acid, chlorogenic acid, 4,5-di- $O$-caffeoylquinic acid, 3,5-di- $O$-caffeoylquinic acid, 3,4-di- $O$ caffeoylquinic acid, and 3,4,5-tri- $O$-caffeoylquinic acid. Most of the phenolic compounds were highest in leaves from plants grown at $20{ }^{\circ} \mathrm{C}$ without shading except 4,5-di- $O$-caffeoylquinic acid. The results indicate that growing leaves under moderately high temperatures and in full sun enhances the accumulation of phenolic components. These phenolic components have possible value in enhancing human health.
\end{abstract}

The consumption of sweetpotato greens as a fresh vegetable in some parts of the world (As-Saqui, 1982; Nwinyi, 1992; Villareal et al., 1982) indicates that they are acceptable as a leafy vegetable. Horticulturists and food scientists, faced with the problem of feeding the world's hungry, are becoming increasingly interested in previously neglected tropical green leafy vegetables like sweetpotato greens. Since sweetpotato leaves can be harvested several times in a year their annual yield is ultimately higher than many other green vegetables. Furthermore, sweetpotato leaves are one of the few vegetables that can be grown easily during the monsoon seasons of the tropics, and are usually the only greens available in some countries after a flood or typhoon. They are rich in vitamin B, iron, calcium, zinc and protein (Pace et al., 1985), and are more tolerant of diseases, pests (Asian Vegetable Research and Development Center, 1985), and high moisture than many other leafy vegetables grown in the tropics (Woolfe, 1992). Our previous reports revealed that sweetpotato leaves are an excellent source of antioxidative compounds, namely polyphenolics (Islam et al., 2002a; Yoshimoto, 2001). In addition, sweetpotato leaves can also be used in noodles, breads, drinks, and confectioneries.

Phenolic compounds are a diverse group of secondary metabolites present in higher plants that play important roles in the structure of plants and are involved in a number of metabolic pathways (Harborne, 1980). Plant phenolics, because of their diversity and extensive distribution, can be argued to be an important group of natural antioxidants, and contribute to organoleptic and nutritional qualities of fruit and vegetables. Phenolic compounds recently have

Received for publication 3 June 2002. Accepted for publication 7 Nov. 2002. This research project was funded in part through STA (Science and Technology Agency of Japanese Government) fellowship to Md. S. Islam provided by the Japan International Science and Technology Exchange Center (JISTEC).

${ }^{1}$ Corresponding author; current address: University of Arkansas at Pine Bluff, Department of Agriculture, Plant Physiology and Nutrition (Horticulture), 1200 North University Drive, Mail Slot 4913, Pine Bluff, AR 71601; e-mail islam_s@uapb.edu.

${ }^{2}$ Corresponding author; e-mail mak825@affrc.go.jp. attracted special attention in that they are thought to protect the human body from oxidative stress, which may cause the onset of cancer, aging, and cardiovascular diseases (Huang and Ferraro, 1991; Kaul and Khanduja, 1998; Peluso et al., 1995; Robards et al., 1999; Shahrzed and Bitsch, 1996; Shimozono etal., 1996; Yoshimoto et al., 1999). Antioxidative capacity of fruit and vegetables is influenced by genetic as well as environmental factors. The measurement of total antioxidant capacity may be an effective tool for use in fruit and vegetable breeding programs designed to increase antioxidant components available for human consumption. Since the natural production environment is variable, controlled growing conditions are needed to ascertain environmental factors affecting antioxidant properties. The investigation of the effects of temperature and shading on phenolic content and radical scavenging activity (RSA) of sweetpotato leaves may identify new methods to enhance its nutritional value. The aim of the present study is to identify suitable growing conditions to enhance desired bioactive compounds.

\section{Materials and Methods}

Plant Materials and Cultural methods. Sweetpotato tips (top 10cm) of 'Shimon-1' (S-1), 'Kyushu-119' (K-119), and 'Elegant Summer' (ES), which were developed for leaf consumption, are harvested from plants grown at the Department of Upland Farming Research of the National Agricultural Research Center for Kyushu Okinawa Region at Miyazaki, Japan. The average air temperature (May to October) of the experimental location was $25^{\circ} \mathrm{C}$. Cuttings were planted in sterilized soil in $12 \mathrm{~cm}$ vinyl pots and placed in a greenhouse. Six weeks after planting, pots were transferred into a greenhouse having a constant temperature of $25 \pm 2{ }^{\circ} \mathrm{C}$. There were five pots, which each served as a replication per treatment and they were arranged in a randomized block design. Temperature and shading experiments were done in separate greenhouses using the above three cultivars. After seven days, the pots were transferred 


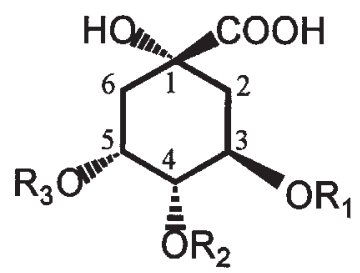

Quinic acid

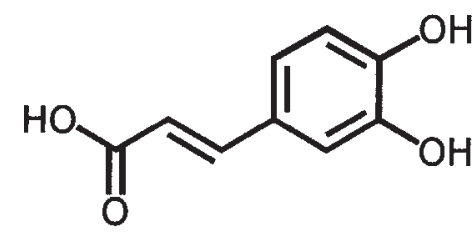

Caffeic acid

$\begin{array}{lccc} & \mathrm{R}_{1} & \mathrm{R}_{2} & \mathrm{R}_{3} \\ \text { Chlorogenic acid: } & \text { caffeic } & \mathrm{H} & \mathrm{H} \\ \text { 4,5-diCQA: } & \mathrm{H} & \text { caffeic } & \text { caffeic } \\ \text { 3,5-diCQA: } & \text { caffeic } & \mathrm{H} & \text { caffeic } \\ \text { 3,4-diCQA: } & \text { caffeic } & \text { caffeic } & \mathrm{H} \\ \text { 3,4,5-triCQA: } & \text { caffeic } & \text { caffeic } & \text { caffeic }\end{array}$

Fig. 1. Chemical structures of the hydroxycinnamate esters in sweetpotato leaves.

into individual greenhouses having temperatures of $20 \pm 1.5^{\circ} \mathrm{C}, 25$ $\pm 2^{\circ} \mathrm{C}$ and $30 \pm 2.5^{\circ} \mathrm{C}$. The shading experiment was conducted using $80 \%, 40 \%$ and $0 \%$ shading. Shading was achieved using commercial shading materials purchased from Nippon Wide Cloth Co. Ltd, Osaka, Japan (for 40\% shading), and Dio Kasei Co., Ltd., Tokyo, Japan (for 80\% shading). The light intensity was checked using a illuminance meter (model T-1H; Minolta Co. Ltd., Osaka, Japan). After $7 \mathrm{~d}$ of continuous treatment, all the leaves (20 to 25 leaves) from each plant were harvested, washed gently, put into prelabeled vinyl bags, and immediately frozen at $-70^{\circ} \mathrm{C}$. The following day the frozen samples were freeze-dried for $48 \mathrm{~h}$ in a vacuum freeze dryer (model TR-PK-3-80; Trio Sciences Co, Ltd., Tokyo, Japan) with a plate temperature of 27 to $30^{\circ} \mathrm{C}$. The freeze-dried samples were powdered using a blender prior to analysis.

Extraction AND MEASUREMENT OF TOTAL PhENOLICS. Total phenolics were measured by the procedure described by Coseteng and Lee (1987) with a slight modification. The lyophilized powdered sweetpotato leaf tissue $(10 \mathrm{mg})$ was vigorously mixed with 1:10 (mg. $\left.\mathrm{mL}^{-1}\right) 80 \%$ aqueous ethanol solution. The mixture was boiled for $5 \mathrm{~min}$ under a hood, centrifuged at $5000 g_{\mathrm{n}}$ for $10 \mathrm{~min}$, and the supernatant was collected. The residue was mixed with $5 \mathrm{~mL}$ of $80 \%$ aqueous ethanol, boiled for $5 \mathrm{~min}$ to reextract the phenolics and centrifuged under the same conditions. The extracts were combined, made up to $10 \mathrm{~mL}$, and used for the measurement of total phenolics. The alcohol extract was diluted to obtain an absorbance reading within the range of the standards ( 40 to $800 \mathrm{mg}$ chlorogenic acid/ $\mathrm{mL}$ ). The absorbance was measured at $600 \mathrm{~nm}$ with a dual wavelength flying spot scanning densitometer (Shimadzu Co., Kyoto, Japan), with a microplate system. The results were expressed as $\mathrm{g} /$ $100 \mathrm{~g}$ dry weight (DW).

IDENTIFICATION OF ISOLATED SWEETPOTATO LEAF PHENOLICS. The dried leaves of sweetpotato $(150 \mathrm{~g})$ were extracted twice by shaking with $2 \mathrm{~L}$ of $100 \%$ methanol at room temperature. The dried extract $(17 \mathrm{~g})$ was partitioned between benzene and water (50:50). The water layer $(8 \mathrm{~g})$ was fractionated on a adsorption chromatography using MCI gel CHP20P column $(50 \times 350 \mathrm{~mm}$ i.d., 75 to $150 \mu \mathrm{m}$, styrene polymer, Mitsubishi Chemical Ind. Ltd., Tokyo, Japan) equilibrated with deionized water and adsorbed components were eluted with $20 \%, 40 \%, 60 \%, 80 \%$ and $100 \%$ methanol successively. The $40 \%$ methanol eluate contained mainly caffeic acid (CA) and chlorogenic acid (ChA), while the $60 \%$ methanol eluate mainly di$O$-caffeoylquinic acids and 3,4,5-tri- $O$-caffeoylquinic acid. These eluates were each further fractionated on a reversed-phase chroma- tography using an ODS column $(25 \times 140 \mathrm{~mm}$ i.d., 30 to $50 \mu \mathrm{m}$, Fuji Silisia Ltd., Nagoya, Japan) using $20 \%$ to $70 \%$ methanol give CA $(15 \mathrm{mg} / 150 \mathrm{~g} \mathrm{DW})$, ChA $(400 \mathrm{mg} / 150 \mathrm{~g} \mathrm{DW}), 3,4-\mathrm{di}-O$ caffeoylquinic acid (3,4-diCQA) $(2 \mathrm{mg} / 150 \mathrm{~g}$ DW), 3,5-di- $O$ caffeoylquinic acid (3,5-diCQA) $(60 \mathrm{mg} / 150 \mathrm{~g} \mathrm{DW}), 4,5$-di- $O$ caffeoylquinic acid (4,5-diCQA) (21 mg/150 g DW) and 3,4,5-tri$O$-caffeoylquinic acid (3,4,5-triCQA) $(2 \mathrm{mg} / 150 \mathrm{~g} \mathrm{DW})$. The above phenolics were identified as described in a previous paper (Islam et al., 2002b). The chemical structures of these phenolic compounds are shown in Fig. 1.

Quantification of Phenolic aCids by RP-HPLC. The lyophilized, powdered sweetpotato leaf tissue $(50 \mathrm{mg})$ was vigorously mixed with $4 \mathrm{~mL}$ of $80 \%$ ethanol in a capped centrifuge tube. The mixture was boiled for $5 \mathrm{~min}$ in a hood and centrifuged at $3000 \mathrm{~g}_{\mathrm{n}}$ for $10 \mathrm{~min}$. The supernatant was filtered through a cellulose acetate membrane filter $(0.20 \mathrm{~mm}$, Advantec, Tokyo, Japan). A $5-\mu \mathrm{L}$ portion of the filtrate was injected into the HPLC system and eluted as described below. The HPLC system consisted of two model LC10AT pumps, a model SIL-10AXL autoinjector, a model CTO10AC column oven, and a model SPD-M10AVP photodiode array UV-VIS detector (Shimadzu, Co., Kyoto, Japan). The column was a YMC-Pack ODS-AM AM-302 $(150 \times 4.6$ mm i.d., $5-\mu \mathrm{m}$ particles; YMC, Kyoto, Japan). The column oven temperature was set at 40 ${ }^{\circ} \mathrm{C}$. The mobile phase consisted of water containing $0.2 \%(\mathrm{v} / \mathrm{v})$ formic acid (A) and methanol (B). Elution was performed with a linear gradient as follows: $2 \% \mathrm{~B}$ from 0 to $15 \mathrm{~min}, 2 \%$ to $45 \% \mathrm{~B}$ from 15 to $50 \mathrm{~min}$, and $45 \% \mathrm{~B}$ from 50 to $65 \mathrm{~min}$. The flow rate was 1 $\mathrm{mL} \cdot \mathrm{min}^{-1}$. The phenolics were detected at $326 \mathrm{~nm}$. The retention times $\left(t_{R}\right)$ of the phenolics compounds were compared with those of purified phenolics from sweetpotato leaves used as authentic standard (purity $>97 \%$ estimated by the HPLC analysis) (Islam et al., 2002b).

Measurement of Radical SCAVENGING aCtivity USING THE DPPH METHOD. The radical scavenging activity (RSA) as measured according to Brand-Williams et al. (1995) with slight modifications. 1,1-Diphenyl-2-picrylhydrazyl (DPPH) was used as a stable radical. All reactions were run in a 96 well microplate with a total volume of $300 \mu \mathrm{L}$. A $75-\mu \mathrm{L}$ sample (80\% ethanol extract) was combined with $150 \mu \mathrm{L} 0.1$ м 2-(N-morpholino) ethanesulfonic acid (MES) (pH 6.0) and $75 \mu \mathrm{L} \mathrm{DPPH} \mathrm{in} \mathrm{50 \%} \mathrm{ethanol} \mathrm{in} \mathrm{the} \mathrm{microplate}$ well and mixed. For the control, $75 \mu \mathrm{L}$ of $80 \%$ ethanol was used in place of the sample. The reaction mixtures were shaken and held for $2 \mathrm{~min}$ at room temperature in the dark. Trolox (6-hydroxy-2, 5,7,8tetramethyl-chroman-2-carboxylic acid) was used as the reference antioxidant compound and $80 \%$ ethanol was used as the blank solution (without DPPH). The decrease in absorbance of DPPH at $520 \mathrm{~nm}$ was measured within $2 \mathrm{~min}$. All samples were analyzed in triplicate. The RSA of samples (antioxidants) was expressed in terms of $\mathrm{IC}_{50}$ (concentration in $\mu \mathrm{mol}$ Trolox $/ \mathrm{mg} \mathrm{DW}$ required for a $50 \%$ decrease in absorbance of the DPPH radical). A plot of absorbance vs. concentration was made to calculate $\mathrm{IC}_{50}$. The results were expressed as $\mu$ mole Trolox/mg DW.

Chemicals. ChA was purchased from Sigma Chemical (St. Louis, Mo.). Trolox was obtained from Aldrich Chemical Co. (Milw., Wis.).CA, DPPH and other chemicals used were the highest grade available supplied by Wako Pure Chemicals Industries Ltd., Osaka, Japan.

Statistics. A randomized complete block design with five replications was used. Data for the different parameters were analyzed by analysis of variance (ANOVA) procedure, and the level of significance was calculated from the $\mathrm{F}$ value of ANOVA using the Excel Statistics 2000 program package for Windows (Social 
Table 1. Effect of temperature on the total leaf phenolic content of sweetpotato cultivars. Each value is the mean of five replications \pm standard error.

\begin{tabular}{|c|c|c|c|c|c|}
\hline \multirow{2}{*}{$\begin{array}{l}\text { Temp } \\
\left({ }^{\circ} \mathrm{C}\right) \\
\end{array}$} & \multicolumn{3}{|c|}{ Total phenolic content (g/100 g dry wt) } & \multirow{2}{*}{$\begin{array}{l}\operatorname{LSD}^{z} \\
(1 \%)\end{array}$} & \multirow{2}{*}{$\begin{array}{l}\text { LSD } \\
(5 \%)\end{array}$} \\
\hline & Simon-1 & Kyushu-119 & Elegant Summer & & \\
\hline 20 & $10.1 \pm 0.32$ & $7.7 \pm 0.33$ & $7.0 \pm 0.28$ & 1.52 & 1.08 \\
\hline 25 & $9.5 \pm 0.25$ & $8.2 \pm 0.34$ & $7.3 \pm 0.27$ & 1.41 & 1.01 \\
\hline 30 & $9.0 \pm 0.19$ & $7.4 \pm 0.16$ & $6.6 \pm 0.24$ & 0.99 & 0.71 \\
\hline $\operatorname{LSD}(1 \%)$ & 1.29 & NS & NS & & \\
\hline$(5 \%)$ & 0.92 & & & & \\
\hline
\end{tabular}

${ }^{\mathrm{z} F o r}$ cultivar.

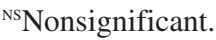

Table 2. Effect of shading on the leaf phenolic content of sweetpotato cultivars. Each value is the mean of five replications \pm standard error.

\begin{tabular}{|c|c|c|c|c|c|}
\hline \multirow{2}{*}{$\begin{array}{l}\text { Shading } \\
(\%)\end{array}$} & \multicolumn{3}{|c|}{ Total phenolic content (g/100 g dry wt) } & \multirow{2}{*}{$\begin{array}{l}\mathrm{LSD}^{\mathrm{z}} \\
(1 \%)\end{array}$} & \multirow{2}{*}{$\begin{array}{l}\text { LSD } \\
(5 \%)\end{array}$} \\
\hline & Simon-1 & Kyushu-119 & Elegant Summer & & \\
\hline 0 & $9.82 \pm 0.21$ & $8.11 \pm 0.34$ & $7.61 \pm 0.21$ & 1.27 & 0.90 \\
\hline 40 & $7.28 \pm 0.28$ & $6.87 \pm 0.16$ & $6.38 \pm 0.16$ & 1.01 & 0.72 \\
\hline 80 & $6.79 \pm 0.12$ & $6.18 \pm 0.21$ & $6.42 \pm 0.19$ & 0.85 & 0.61 \\
\hline $\operatorname{LSD}(1 \%)$ & 1.02 & 1.21 & 0.92 & & \\
\hline$(5 \%)$ & 0.73 & 0.86 & 0.65 & & \\
\hline
\end{tabular}

${ }^{\mathrm{z} F o r}$ cultivar.

Table 3. Effect of temperature on the leaf radical scavenging activity of sweetpotato cultivars. Each value is the mean of five replications \pm standard error.

\begin{tabular}{|c|c|c|c|c|c|}
\hline \multirow{2}{*}{$\begin{array}{l}\text { Temp } \\
\left({ }^{\circ} \mathrm{C}\right)\end{array}$} & \multicolumn{3}{|c|}{ Radical scavenging activity ( $\mu \mathrm{mol}$ Trolox/mg dry wt) } & \multirow{2}{*}{$\begin{array}{l}\mathrm{LSD}^{\mathrm{Z}} \\
(1 \%)\end{array}$} & \multirow{2}{*}{$\begin{array}{l}\text { LSD } \\
(5 \%)\end{array}$} \\
\hline & Simon-1 & Kyushu-119 & Elegant Summer & & \\
\hline 20 & $0.99 \pm 0.18$ & $0.54 \pm 0.04$ & $0.51 \pm 0.04$ & 0.52 & 0.37 \\
\hline 25 & $0.67 \pm 0.13$ & $0.57 \pm 0.03$ & $0.47 \pm 0.03$ & 0.38 & 0.27 \\
\hline 30 & $0.51 \pm 0.04$ & $0.46 \pm 0.03$ & $0.42 \pm 0.04$ & 0.18 & 0.13 \\
\hline $\operatorname{LSD}(1 \%)$ & 0.63 & NS & NS & & \\
\hline$(5 \%)$ & 0.45 & & & & \\
\hline
\end{tabular}

For cultivar.

Ns Nonsignificant.

Table 4. Effect of artificial shading on the leaf radical scavenging activity of sweetpotato cultivars. Each value is the mean of five replications \pm standard error.

\begin{tabular}{|c|c|c|c|c|c|}
\hline \multirow{2}{*}{$\begin{array}{l}\text { Shading } \\
(\%)\end{array}$} & \multicolumn{3}{|c|}{ Radical scavenging activity ( $\mu \mathrm{mol}$ Trolox/mg dry wt) } & \multirow{2}{*}{$\begin{array}{l}\mathrm{LSD}^{2} \\
(1 \%)\end{array}$} & \multirow{2}{*}{$\begin{array}{l}\text { LSD } \\
(5 \%)\end{array}$} \\
\hline & Simon-1 & Kyushu-119 & Elegant Summer & & \\
\hline 0 & $0.70 \pm 0.06$ & $0.68 \pm 0.03$ & $0.57 \pm 0.04$ & 0.22 & 0.15 \\
\hline 40 & $0.57 \pm 0.06$ & $0.51 \pm 0.05$ & $0.53 \pm 0.08$ & 0.26 & 0.18 \\
\hline 80 & $0.53 \pm 0.04$ & $0.52 \pm 0.06$ & $0.54 \pm 0.06$ & 0.24 & 0.17 \\
\hline $\operatorname{LSD}(1 \%)$ & 0.24 & 0.23 & NS & & \\
\hline$(5 \%)$ & 0.17 & 0.16 & & & \\
\hline
\end{tabular}

${ }^{\mathrm{z}}$ For cultivar.

${ }^{\text {NSN} N o n s i g n i f i c a n t . ~}$

Information Service Co. Ltd., Tokyo, Japan). The relation between total polyphenols and RSA were described with correlation analysis using the above statistical program.

\section{Results}

Temperature AND Shading EFFECTS. The effect of temperature on the total leaf phenolic content of sweetpotato cultivars is shown in Table 1 . The phenolics content differed $(P<0.01)$ among the cultivars studied and the leaves from ' $\mathrm{S}-1$ ' had the highest content followed by 'K-119' and 'ES'. The 'S-1' sweetpotato leaves grown at $20^{\circ} \mathrm{C}$ had the highest phenolic content and was greater than that of 'S-1' leaves grown at $30^{\circ} \mathrm{C}$. Although total leaf phenolic content of other cultivars did not differ significantly with growing temperature, levels in leaves grown at 20 and $25^{\circ} \mathrm{C}$ were always greater than that of leaves grown at $30{ }^{\circ} \mathrm{C}$. Shading also affected leaf phenolic content. Sweetpotato leaves in the $0 \%$ shading treatment had a significantly greater accumulation of total phenolics than the $40 \%$ and $80 \%$ shading treatments in all cultivars (Table 2). The effect of temperature on the RSA in sweetpotato leaves showed a trend similar to temperature effects on phenolic accumulation (Table 3 ). The RSA was significantly greater in $20^{\circ} \mathrm{C}$ grown ' $\mathrm{S}-1$ ' leaves than in $30{ }^{\circ} \mathrm{C}$ leaves, but the other cultivars did not differ with the temperature treatments. Like polyphenol accumulation, the RSA in leaves from $0 \%$ shading were significantly greater than $40 \%$ and $80 \%$ shading except in 'ES' (Table 4$)$. There was a significant $(P<$ 


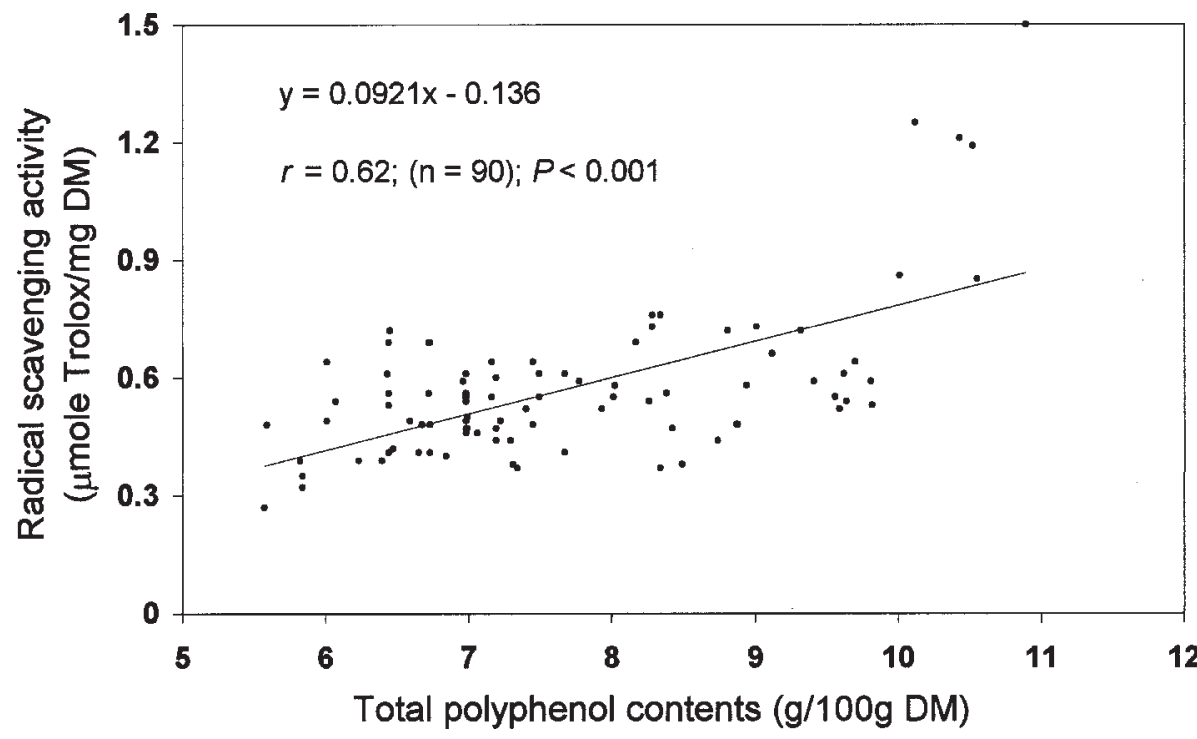

Fig. 2. Linear correlations between the total polyphenol contents ( $g / 100 \mathrm{~g}$ dry weight) and radical scavenging activities ( $\mu \mathrm{mol}$ Trolox/mg dry weight) of sweetpotato leaves.

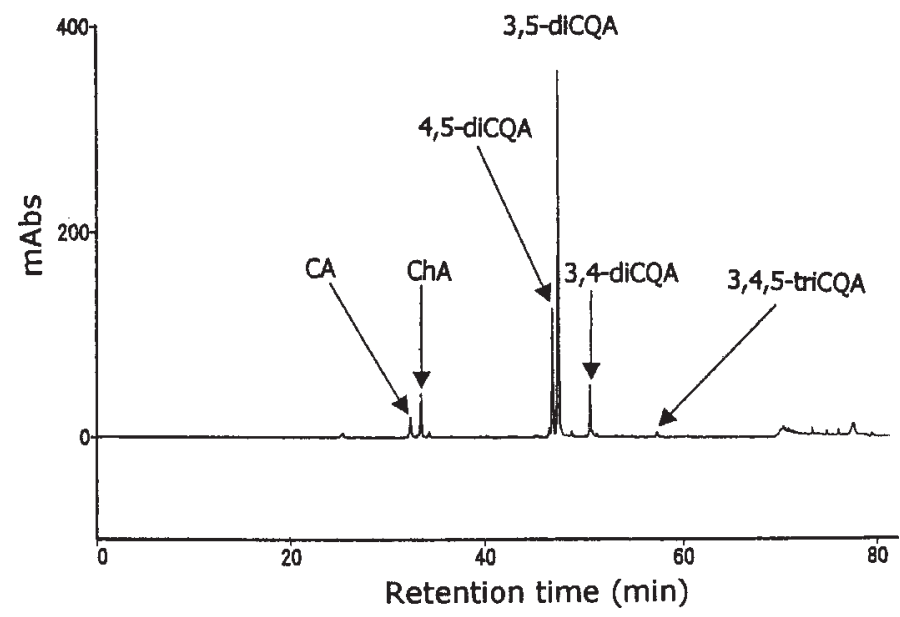

Fig. 3. A representative reverse-phase HPLC $\left(\mathrm{C}_{18}\right)$ chromatogram for polyphenolic compounds in sweetpotato leaf extracts. Detector absorbance was at $326 \mathrm{~nm}$. $\mathrm{CA}=$ caffeic acid $(32.27 \pm 0.12 \mathrm{~min}) ; \mathrm{ChA}=$ chlorogenic acid $(33.42 \pm 0.18$ $\min ) ; 4,5$-diCQA $=4,5$-di- $O$-caffeoylquinic acid $(46.72 \pm 0.14 \mathrm{~min})$; 3,5diCQA $=3,5$-di- $O$-caffeoylquinic acid (47.34 $\pm 0.17 \mathrm{~min}) ; 3,4$-diCQA = 3,4-di$O$-caffeoylquinic acid $(50.55 \pm 0.22 \mathrm{~min}) ; 3,4,5$-triCQA $=3,4,5$-tri- $O$ caffeoylquinic acid (57.25 $\pm 0.13 \mathrm{~min})$.

0.001) linear correlation ( $r=0.62, \mathrm{n}=90)$ observed between RSA and total phenolics accumulation in sweetpotato leaves (Fig. 2).

IDENTIFICATION OF PHENOLIC COMPOUNDS AND THE EFFECT OF TEMPERATURE AND SHADING. Our extraction method and RP-HPLC analysis identified six different phenolic compounds in sweetpotato leaves (Fig. 3). All the HPLC profiles of the treatments displayed the same peaks indicating no qualitative difference among cultivars (data not shown). However, the peak areas differed with cultivars and experimental treatments. Peaks were identified as CA (retention time $\left.\left(t_{R}\right)=32.27 \pm 0.12 \mathrm{~min}\right), \mathrm{ChA}\left(t_{R}=33.42 \pm 0.18 \mathrm{~min}\right), 4,5-$ $\operatorname{diCQA}\left(t_{R}=46.72 \pm 0.14 \mathrm{~min}\right), 3,5-\operatorname{diCQA}\left(t_{R}=47.34 \pm 0.17 \mathrm{~min}\right)$, $3,4-$ diCQA $\left(t_{R}=50.55 \pm 0.22 \mathrm{~min}\right)$ and 3,4,5-triCQA $\left(t_{R}=57.25 \pm\right.$ $0.13 \mathrm{~min})$. All the cultivars studied showed a similar chromatographic pattern for the above caffeic acid derivatives and 3,5diCQA and 4,5-diCQA were the dominant phenolics. Temperature affected phenolic composition in sweetpotato leaves (Fig. 4). In all three cultivars there were no significant differences observed in the concentration of CA, ChA, 3,4-diCQA and 3,4,5-triCQA among the temperature treatments. However, 3,5-diCQA content was lower in leaves grown at $30^{\circ} \mathrm{C}$ as compared with those grown at 20 and $25^{\circ} \mathrm{C}$, and the content of 4,5-diCQA was highest in leaves grown at $30{ }^{\circ} \mathrm{C}$. The shading treatment also influenced the phenolic composition of sweetpotato leaves (Fig. 5). The highest content of phenolic compounds from the leaves of all 3 cultivars was in plants grown without shading. Similar to the temperature responses, the 3,5-diCQA and 4,5-diCQA were also the phenolics most affected by shading treatments in all the cultivars studied. In the case of ' $\mathrm{S}-1$ ', there was little effect of the shading treatments. However, in 'K-119' and 'ES', shading decreased the concentration of phenolic compounds with the exception of CA and 3,4,5-triCQA.

\section{Discussion}

Our recent studies revealed that sweetpotato leaves were an excellent source of antioxidative phenolic compounds (Islam et al., 2002a; Yoshimoto, 2001). In the present study, total phenolic concentration in sweetpotato leaves ranged from $6.18 \mathrm{~g} / 100 \mathrm{~g} \mathrm{DW}$ to $10.1 \mathrm{~g} / 100 \mathrm{~g} \mathrm{DW}$ (Table 1 and 2), which is high when compared to sweetpotato storage roots (Walter et al., 1979) and potato tubers (Lugasi et al., 1999). The results of this study suggest that plants grown under moderate temperature and without shading accumulate a higher concentration of leaf phenolics than plant grown under high temperatures and shaded conditions (Tables 1-4). The decrease in phenolic content in leaves grown under shade is probably due to the reduced stimulation of phenolic production by light. Moriyama et al. (1999) reported that $60 \%$ and $80 \%$ shading decreased the phenolic content of tea leaves compared to $0 \%$ shading. The present results also indicate that moderate temperatures (20 to $\left.25^{\circ} \mathrm{C}\right)$ enhanced synthesis and/or warm temperature $\left(30^{\circ} \mathrm{C}\right)$ enhanced degradation of sweetpotato leaf phenolics.

The RSA of sweetpotato leaves exhibited similar trends as the phenolic content in all the cultivars studied. Also there was a strong relationship $(P<0.001)$ between RSA and total polyphenol content of sweetpotato leaves (Fig. 2). Thus, the RSA of sweetpotato leaves is due primarily to their phenolic contents. Although different among the treatments studied, sweetpotato leaves had a high RSA. The present data and our recent report suggests that sweetpotato leaves might be expected to have physiologically active properties by showing strong antimutagenicity against Trp-P-1 using Salmonella typhimurium TA 98 (Yoshimoto et al., 2002).

We have analyzed the phenolic composition of sweetpotato leaves by using RP-HPLC. Although HPLC profiles of the treatment tested showed the peaks at the same $t_{R}$, there was wide variation in quantities of individual phenolic compounds in sweetpotato leaves in relation to cultivars and growing conditions. These results suggest that the phenolic compounds in sweetpotato leaves are distributed as per the following order: 3,5-diCQA > 4,5-diCQA > $\mathrm{ChA}>3,4$-diCQA $>$ CA > 3,4,5-triCQA (Figs. 4 and 5). The leaves grown under moderate temperature and without shading accumulated the highest concentration of all the phenolic compounds with 
the exception of 4,5-diCQA. Therefore, the high temperature treatment $\left(30{ }^{\circ} \mathrm{C}\right)$ reduced the phenolic compounds in sweetpotato leaves, but moderate temperatures namely $20{ }^{\circ} \mathrm{C}$ enhanced the accumulation of the individual polyphenolics. Chlorogenic acid content of sweetpotato leaves was much higher than that of sweetpotato storage roots (Walter etal., 1979), potato tubers (Lugasi et al., 1999), and apple fruit (Murata et al., 1995) and it has various physiological functions in both animal and humans (Kapil et al., 1995; Tsuchiya et al., 1996; Yagasaki et al., 2000). Among other phenolic compounds, CA was the most effective inhibitor of tumor promotion in mice skin and, ChA, 3,4-diCQA, 3, 5-diCQA, and 4,5diCQA, which were extracted from steamed sweetpotato suppressed the melanogenesis equally (Kaul and Kkanduja, 1998; Shimozono et al., 1996). Furthermore, the 3,4,5-triCQA exhibited a greater selective inhibition of HIV replication than 4,5-diCQA,

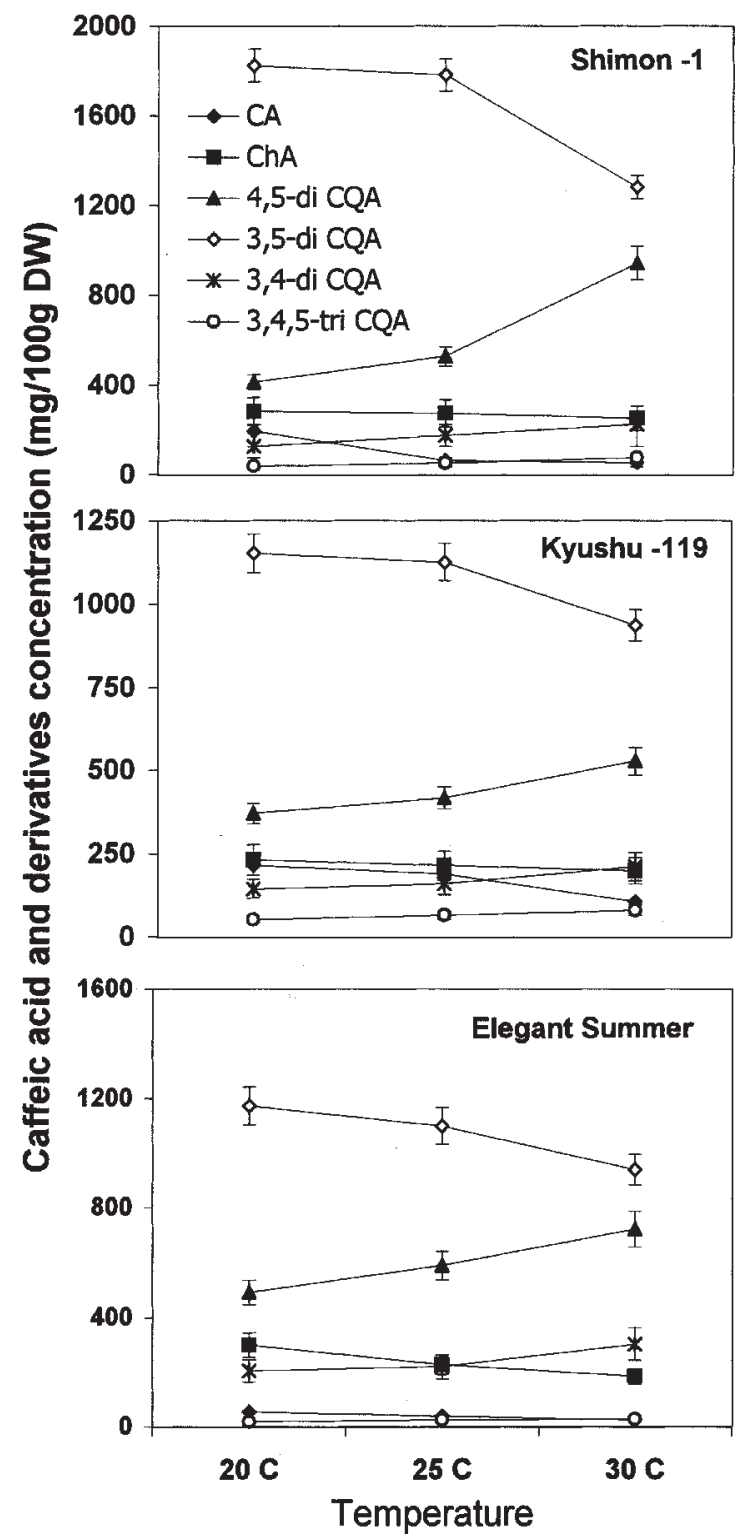

Fig. 4. Effect of temperature on the concentration of polyphenolic compounds in the leaves of three sweetpotato cultivars. Bars indicate the standard error of the mean of five replications, when absent it falls under the symbol. $\mathrm{CA}=$ caffeic acid, ChA = chlorogenic acid, 4,5-diCQA = 4,5-di- $O$-caffeoylquinic acid, 3,5diCQA $=3,5$-di- $O$-caffeoylquinic acid, 3,4-diCQA = 3,4-di- $O$-caffeoylquinic acid, 3,4,5-triCQA = 3,4,5-tri- $O$-caffeoylquinic acid. and CA had only slight anti HIV activity (Mahmood et al., 1993).

These results may help to get the desired phenolic compounds in sweetpotato leaves by manipulating the growing conditions, and also be of use in future breeding programs designed to increase antioxidant components for human health. The results also indicate that growth of sweetpotato leaves under moderate temperatures and in full sun enhances the accumulation of phenolic components.

\section{Literature Cited}

Asian Vegetable Research and Development Center. 1985. Composition of edible fiber in sweetpotato tips. Asian Veg. Res. Dev. Ctr. Progr. Rpt. 1985:310-313.

As-Saqui, M.A. 1982. Sweetpotato and its potential impact in Liberia, p. 59. In: R.L. Villareal and T.D. Griggs (eds.). Sweetpotato. Proc. 1st Intl. Symp. Asian Veg. Res. Dev. Ctr., Shanhua, Taiwan.

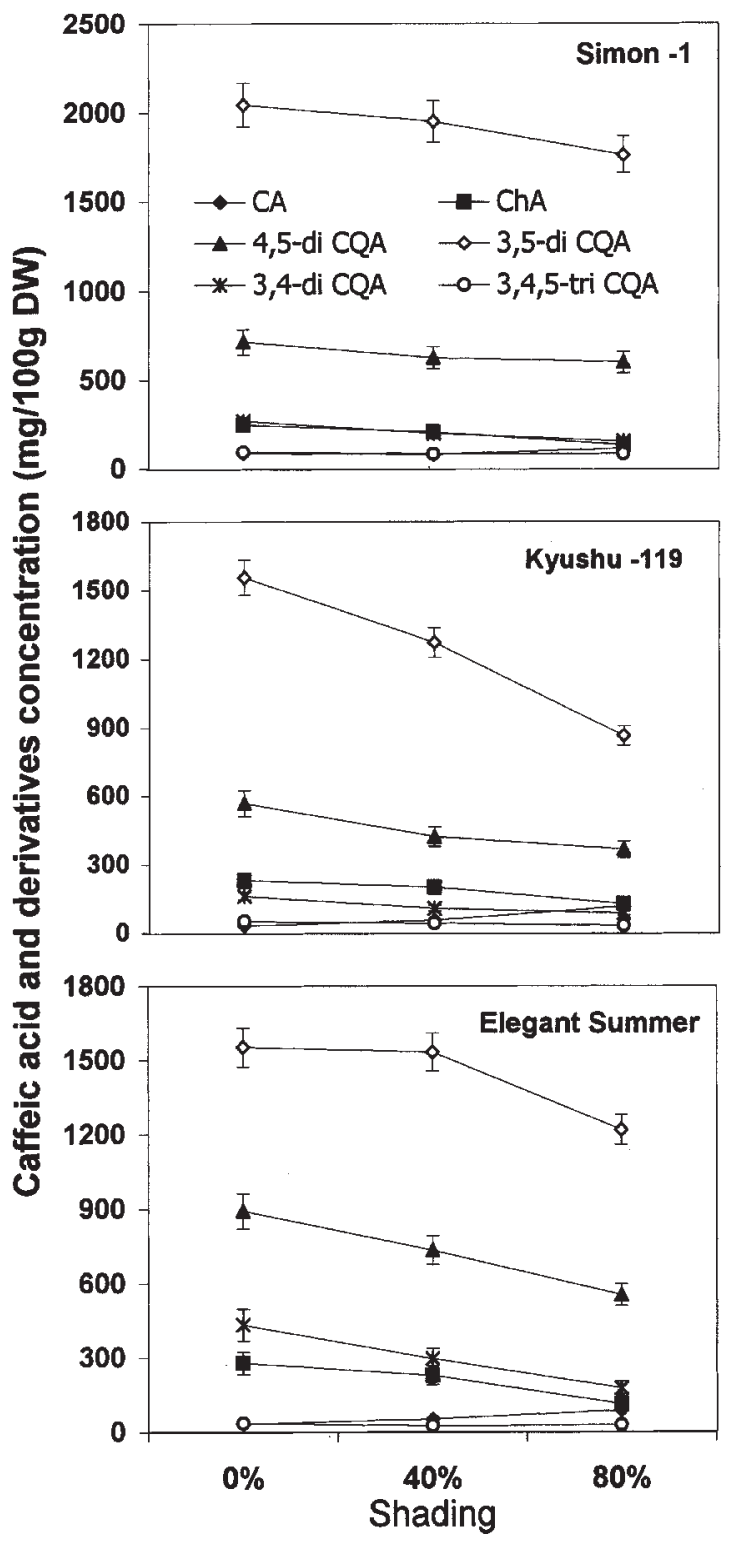

Fig. 5. Effect of artificial shading on the concentration of polyphenolic compounds in the leaves of three sweetpotato cultivars. Bars indicate the standard error of the mean of five replications, when absent it falls under the symbol. CA = caffeic acid, $\mathrm{ChA}=$ chlorogenic acid, 4,5-diCQA = 4,5-di- $O$-caffeoylquinic acid, 3,5diCQA $=3,5$-di- $O$-caffeoylquinic acid, 3,4-diCQA = 3,4-di- $O$-caffeoylquinic acid, 3,4,5-triCQA = 3,4,5-tri- $O$-caffeoylquinic acid. 
Brand-Williams, W., M.E. Cuvelier, and C. Berset. 1995. Use of a free radical method to evaluate antioxidant activity. Lebensm. Wiss. Technol. 28:25-30.

Coseteng, M.Y. and C.Y. Lee. 1987. Changes in apple polyphenoloxidase and polyphenol concentrations in relation to degree of browning. J. Food. Sci. 52:985-989.

Harborne, J.B. 1980. Plant phenolics, p. 329-402. In: E.A. Bell and B.V. Charlwood (eds.). Encyclopedia of plant physiology. new ser., vol. 8. Springer Verlag, Berlin, Germany.

Huang, M.T. and T. Ferraro. 1991. Phenolic compounds in food and cancer prevention, p. 220-238. In: M.T. Hung, C.T. Ho, and C.Y. Lee (eds.). Phenolic compounds in food and their effects on health: Antioxidant cancer prevention. Amer. Chem. Soc. Symp. Ser. 5078.

Islam, M.S., M. Yoshimoto, O. Yamakawa, K. Ishiguro, and M. Yoshinaga. 2002a. Antioxidative compounds in the leaves of sweetpotato genotypes. Sweetpotato Res. Front 13:4.

Islam, M.S., M. Yoshimoto, O. Yahara, S. Okuno, K. Ishiguro, and O. Yamakawa. 2002b. Identification and characterization of foliar polyphenolic composition in sweetpotato (Ipomoea batatas L.) genotypes. J. Agr. Food Chem. 50: 3718-3722.

Kapil, A., I.B. Koul, and O.P. Suri. 1995. Antihepatotoxic effects of chlorogenic acid from Anthocephalus cadamba. Phytotherapy Res. 9:189193.

Kaul, A., and K.L. Khanduja. 1998. Polyphenols inhibit promotional phase of tumorigenesis: Relevance of superoxide radicals. Nutr. Cancer 32:8185.

Lugasi, A., D.P.E. Almedia, and E. Dworschak. 1999. Chlorogenic acid content and antioxidant properties of potato tubers as related to nitrogen fertilization. Acta Alimentaria 28:183-195.

Mahmood, N., P.S. Moore, N.D. Tommasi, F.D. Simone, S. Colman, A.J. Hay, and C. Pizza. 1993. Inhibition of HIV infection by caffeoylquinic acid derivatives. Antiviral Chem. Chemothy 4:235-240.

Moriyama, H., S. Nakamura, S. Egami, and N. Shimizu. 1999. Effect of direct shading treatment on the content of flavor compounds in tea shoot. Kyushu Agr. Res. 61:25.

Murata, M.I.Noda, and S. Homma. 1995. Enzymatic browning of apples on the market: relation between browning, polyphenol content, and polyphenol oxidase. Nippon Shokuhin Kagaku Kogaku Kaishi 42:820-826.

Nwinyi, S.C.O. 1992. Effect of age at shoot removal on tuber and shoot yields at harvest of five sweetpotato (Ipomoea batatas (L.) Lam) culti- vars. Field Crops Res. 29:47-54.

Pace, R.D., T.E. Sibiya, B.R. Phills, and G.G. Dull. 1985. Ca, Fe and Zn content of 'Jewel' sweetpotato greens as affected by harvesting practices. J. Food Sci. 50:940-941.

Peluso, G., V.D. Feo, F.D. Simone, E. Bresciano. 1995. Studies on the inhibitory effects of caffeoylquinic acids on monocyte migration and superoxide anion production. J. Natl. Prod. 58:639-646.

Robards, K., P.D. Prenzler, G. Tucker, P. Swatsitang, and W. Glover. 1999. Phenolic compounds and their role in oxidative processes in fruits. Food Chem. 66:401-436.

Shahrzed, S. and I. Bitsch. 1996. Determination of some pharmacologically active phenolic acids in juices by high-performance liquid chromatography. J. Chromatogr. 741:223-231.

Shimozono, H., M. Kobori, H. Shinmoto, and T. Tsushida. 1996. Suppression of the melanogenesis of mouse melanoma B 16 cells by sweetpotato extract. Nippon Shokuhin Kagaku Kogaku Kaishi 43:313-317.

Tsuchiya, T., O. Suzuki, and K. Igarashi. 1996. Protective effects of chlorogenic acid on paraquat-induced oxidative stress in rats. Biosci. Biotechnol. Biochem. 60:765-768.

Villareal, R.L., S.C. Tsou, H.F. Lo, and S.C. Chiu. 1982. Sweetpotato tips as vegetables, p. 313-320. In: R.L. Villareal and T.D. Griggs (eds.). Sweetpotato. Proc. 1st Intl. Symp. Asian Veg. Res. and Dev. Ctr., Shanhua, Taiwan.

Walter, W.M., A.E. Purcell, and G.K. McCollum. 1979. Use of high pressure liquid chromatography for analysis of sweetpotato phenolics. J. Agr. Food Chem. 27:938-941.

Woolfe, J.A. 1992. Sweetpotato. An untapped food resource. Cambridge Univ. Press, Cambridge, U.K.

Yagasaki, K., Y. Miura, R. Okauchi, and T. Furuse. 2000. Inhibitory effects of chlorogenic acids and its related compounds on the invasion of hepatoma cells in culture. Cytotechnology 33:229-235.

Yoshimoto, M., S. Okuno, S. Yahara, M.S. Islam, K. Ishiguro, and O. Yamakawa, O. 2002. Antimutagenicity of mono-, di-, and tricaffeoylquinic acid derivatives isolated from sweetpotato (Ipomoea batatas L.) leaf. Biosci. Biotechnol. Biochem. 66:2336-2341.

Yoshimoto, M. 2001. New trends of processing and use of sweetpotato in Japan. Farming Japan 35:22-28.

Yoshimoto, M., S. Okuno, M. Yoshinaga, O. Yamakawa, M. Yamaguchi, and J. Yamada. 1999. Antimutagenicity of sweetpotato(Ipomoea batatas) roots. Biosci. Biotechnol. Biochem. 63:537-541. 